\title{
Palmaris Longus Muscle's Prevalence in Different Nations and Interesting Anatomical Variations: Review of the Literature
}

\author{
Dimitriou Ioannis ${ }^{\mathrm{a}, \mathrm{d}}$, Katsourakis Anastasios ${ }^{\mathrm{b}}$, Natsis Konstantinos ${ }^{\mathrm{c}}$, \\ Kostretzis Lazaros ${ }^{\mathrm{a}}$, Noussios Georgios ${ }^{\mathrm{a}}$
}

\begin{abstract}
The prevalence of the palmaris longus (PL) muscle varies more than any other muscle in the human body. Its absence across the world ranges between $1.5 \%$ and $63.9 \%$. It presents with many different anomalies, discovered either clinically, intraoperatively or after anatomical examination of cadavers. This paper includes recent studies and reports about the presence and variations of the PL muscle, thereby illustrating the differences between ethnic groups, as well as emphasizing the different ways of finding it, during daily clinical and surgical practice.
\end{abstract}

Keywords: Palmaris longus; Anatomical variations; Presence; Absence; Agenesis; Anatomical anomalies

\section{Introduction}

The purpose of this review was to investigate published articles concerning the distribution of the palmaris longus (PL) muscle in different populations with a view to highlighting some of the rare anomalies associated with it.

\section{Literature Search Methods}

The research was undertaken electronically to discover all the possible variations of the PL muscle, as earlier reported in

\footnotetext{
Manuscript accepted for publication September 01, 2015

a'Laboratory of Anatomy in the Department of Physical Education and Sports Medicine (Serres), Aristotele University of Thessaloniki, Thessaloniki, Greece bepartment of Surgery, “Agios Dimitrios” General Hospital of Thessaloniki, Thessaloniki, Greece

${ }^{\mathrm{c}}$ Department of Anatomy, Medical School, Aristotele University of Thessaloniki, Thessaloniki, Greece

${ }^{\mathrm{d} C}$ Corresponding Author: Dimitriou Ioannis, Laboratory of Anatomy in the Department of Physical Education and Sports Medicine (Serres), Aristotele University of Thessaloniki, Kanari 7 Stavroupoli, Thessaloniki 56430, Greece. Email: johndim577@yahoo.com
}

doi: http://dx.doi.org/10.14740/jocmr2243w researches conducted with different populations. This review contains information from Medline and Google Scholar from 1944 to 2014. The research was made using keywords such as palmaris longus, anatomical variations, presence, absence, agenesis, and anatomical anomalies.

All related articles were carefully assessed and their conclusions and discussions were taken into consideration in this review. Information about unavailable articles was obtained from the published abstract. The published articles that were studied are presented in the discussion section and were all included to the references.

\section{Literature Results}

The search produced many articles on the prevalence of PL muscle in the world. After careful reading, we chose, for our research, 34 articles that contained studies on populations, 20 articles that reported or concluded interesting cases of PL muscle anomalies and two review articles. All the population studies in our research excluded people with previous injury and deformities of the forearm and were made using at least three clinical tests.

\section{Anatomy}

The PL muscle belongs to the superficial flexor muscles of the forearm. The muscles of the forearm are: 1) the anterior or flexors; 2) the posterior or abductors; and 3) the muscles of the radial area. All these muscles are muscular at the upper end and they are toggled into long thin tendons that extend at the apex of the fingers [1]. The PL muscle belongs to the anterior muscles of the forearm. The anterior muscles form three layers, two superficial and one deep. This muscle belongs to the first superficial layer along with the flexor carpi ulnaris, the flexor carpi radialis and the pronator teres muscle [1-3].

The PL muscle is a thin spindle shaped long slender and fusiform muscle that is found between the flexor muscles, carpi ulnaris and carpi radialis [2-6]. It arises from the medial epicondyle and epicondylar ridge of the humerus [3-6]. It runs downwards and terminates in a long, slender tendon which passes anterior to the transverse carpal ligament, crosses the 
Table 1. Summary of the Percentages of the PL Muscle Agenesis in Each Study $[2,7,10,11,14-26,28-36,38-41]$

\begin{tabular}{|c|c|c|c|}
\hline Research & Country - Nation & Number of participants & Agenesis \\
\hline Offei et al, 2014 [22] & Ghana & 210 & $3.8 \%$ \\
\hline Venter et al, 2014 [32] & South Africa & 706 & $24.4 \%$ \\
\hline Karimi-Jashni et al, 2014 [33] & Iran & 732 & $30.7 \%$ \\
\hline Lahiji et al, 2013 [34] & Iran & 1,000 & $22.8 \%$ \\
\hline Raouf et al, 2013 [18] & Egypt & 386 & $50.8 \%$ \\
\hline Soltani et al, 2012 [35] & USA (Multiethnic) & 516 & $14.9 \%$ Caucasians; $2.9 \%$ Asians; $4.5 \%$ Afro-Americans \\
\hline Osonuga et al, 2012 [2] & Ghana & 226 & $3.1 \%$ \\
\hline Kyung et al, 2012 [23] & South Korea & 269 & $4.1 \%$ \\
\hline Saxena, 2012 [14] & India & 426 & $27 \%$ \\
\hline Sharma et al, 2012 [7] & India & 400 & $16.25 \%$ \\
\hline Morais et al, 2012 [28] & Brazil & 740 & $26.5 \%$ \\
\hline Kigera et al, 2011 [19] & East Africa & 800 & $4.4 \%$ \\
\hline Ertem et al, 2011 [40] & Turkey & 200 & $34.5 \%$ \\
\hline Alves et al, 2011 [29] & Turkey & 200 & $20 \%$ \\
\hline Hiz, $2011[21]$ & Turkey & 1,000 & $15 \%$ \\
\hline Sankar et al, 2011 [30] & India & 942 & $28 \%$ \\
\hline Sater et al, 2010 [26] & Bahrain & 1,043 & $36.8 \%$ \\
\hline Ndou et al, 2010 [36] & South Africa & 201 & $11.5 \%$ \\
\hline Enye et al, 2010 [15] & Lagos & 500 & $12.6 \%$ \\
\hline Eric et al, 2010 [38] & Serbia & 800 & $37.5 \%$ \\
\hline Mbaka and Adedayo, 2009 [10] & Nigeria & 600 & $6.7 \%$ \\
\hline Kose et al, 2009 [11] & Turkey & 1,350 & $26.6 \%$ \\
\hline Gangata, 2009 [20] & Zimbabwe & 890 & $1.5 \%$ \\
\hline Kapoor et al, 2008 [39] & India & 500 & $17.2 \%$ \\
\hline Oluyemi et al, 2008 [16] & Nigeria & 600 & $31.3 \%$ \\
\hline Roohi et al, 2007 [41] & Malaysia & 450 & $11.3 \%$ \\
\hline Sebastin et al, 2006 [17] & China & 329 & $4.6 \%$ \\
\hline Thompson et al, 2001 [31] & Caucasians & 300 & $25 \%$ \\
\hline Ceyhan and Mavt, 1997 [25] & Turkey & 7,000 & $63.9 \%$ \\
\hline Troha et al, 1990 [24] & Caucasians & 200 & $5.5 \%$ \\
\hline
\end{tabular}

retinaculum, becomes flat and enters the palmar aponeurosis of the hand, anterior to the flexor retinaculum [6-8]. Its innervation comes from branches of the median nerve $[1,3]$.

\section{Physiology}

The PL muscle flexes the wrist weakly as an accessory flexor muscle. Its main function is to serve as an anchor of the fascia, as it tenses the skin and the palmar fascia of the hand, shearing the forces to the palmar aponeurosis in a distal direction [2, 9-11]. Another use of the muscle is to abduct the thumb [11]. This role is due to its slender move over the long adaptor of the thumb [10-12]. Generally, its role is negligible and this is the reason why it is lost in many operations without cost to the function of the forearm or the wrist [13].

\section{Clinical Examination}

Physical examination of the PL muscle is made using different techniques. Using these sign-techniques, we are able to identify the presence, absence and variations of the PL muscle in the examined person [14-17]. So far, 11 different clinical tests have been referred to in the literature. The most common tests in use are: 1) the standard test or Schaeffer's test: during this test, the person under examination opposes the thumb to the little finger and then flexes the wrist; 2) Mishra's I test: the metacarpophalangeal joints of the person's fingers are passively hyperextended, and then the person is asked to flex 
the wrist; 3) Mishra's II test: the person is asked to abduct the thumb against resistance while having the wrist in palmar flexion; 4) Thompson's test: the person under examination makes a fist and then flexes the wrist while opposing and flexing the thumb over the fingers; 5) Pushpakumar's test or "two finger sign" method: in this test, the person totally extends the index and middle fingers, while the wrist and other fingers are flexed and the thumb is opposed and flexed over the flexed fingers [14-17].

Compared to those mentioned above, there are six other tests that are rarely used to study the agenesis or existence of the PL muscle [18-20]. These tests are: 1) the Lotus sign test: the person forms a cone shape with all his fingers and thumb, along with wrist flexion and thumb abduction $[19,20]$; 2) the four finger sign: the person extends the four fingers with a combination of opposition and flexion of the thumb at the first metacarpophalangeal joint $[19,20] ; 3)$ the open hand technique: the person stretches out all the fingers and extends the wrist slightly $[19,20]$; 4) the Cangata test: the person under examination opposes thumb abduction and resists wrist flexion [20]; 5) the Bhattacharya test: the person flexes the wrist against the resistance of the examiner $[19,20]$; 6) the Hiz-Ediz test, which is the most recently developed test: the examiner applies resistance to the flexed fingers and the wrist while all the fingers are at the opposite position with the wrist slightly flexed $[2,21]$.

\section{Discussion}

The PL muscle is one of the most variable muscles in the human body both in percentage and form. The most common anatomical anomaly in the literature is its absence or the socalled agenesis $[12,15,21]$. The traditional knowledge is that PL muscle is absent in $15 \%$ of the global population [12]. This information was first reported by Reimann et al (1944) and it is still being constantly questioned by many researchers across the world [12]. Many studies investigated the prevalence of the PL muscle and reported its absence among different populations. All the results from the most recent studies are located in Table 1 according the year of publication.

There have been 32 studies that have objectively assessed PL muscle presence. The results showed that its absence prevalence ranges between $1.5 \%$ and $63.9 \%$. The lowest absence was observed in Zimbabwe (1.5\%) with unilateral and bilateral agenesis being $0.9 \%$ and $0.6 \%$, respectively [20]. It was also observed that PL muscle agenesis is very low in black populations because of the fact that the lowest percentages were found in Zimbabwe (1.5\%) [20], Ghana (3.1-3.8\%) [2, 22], East Africa (4.4\%) [19] and Nigeria (6.7\%) [10]. Low percentages of absence were also found in China (4.6\%) [17], South Korea (4.1\%) [23] and Caucasians (5.5\%) [24]. The highest prevalence of PL muscle absence was observed in Turkey in 1997 by Ceyhan and Mavt that noticed the remarkable percentage of $63.9 \%$ of absence [25]. Very high percentages of absence were also found in Egypt (50.8\%) [18] and Bahrain $(36.8 \%)$ [26]. All the other studies that present percentages of absence of the PL muscle in Caucasian, Middle East and Latin American populations were found to have agenesis in percent- ages between those mentioned before.

The current knowledge is that PL muscle absence is more common in women and on the left side. There have been 10 studies that found significant difference between genders in the PL muscle agenesis. Eight studies concluded that PL absence is more common in females $[2,11,18,26-30]$ and only two studies concluded that PL absence is more common in males $[7,31]$. On the other hand, there have been 11 studies that did not find any statistically significant difference between sexes $[10,15,17,21-23,32-36]$. According the side of the body where PL muscle absence is more frequent, there have been 23 studies that examined this connection. PL muscle agenesis was more frequent on the left hand in eight studies $[2,25,29$, $30,34,37-39]$ and on the right hand in two studies [27, 31]. In contrast with these results, 13 studies concluded that statistically there is no difference between the two sides of the body $[7,15-18,21-23,28,32,33,35,36]$.

The PL muscle absence may appear on one side or on both sides of the body. There have been 21 studies that examined the laterality in the PL muscle absence. Bilateral agenesis of the PL muscle was more common in nine studies [11, 16, 18, $25-27,31,37,40]$ and unilateral agenesis was more common in four studies [7, 19, 38, 41]. On the contrary, eight studies noted that unilateral and bilateral absence of the PL muscle had no statistical difference and concluded that PL muscle agenesis is irrelevant to laterality $[17,20-23,32,33,35]$.

The PL muscle agenesis is not connected with hand dominance and this incidence was found statistically significant in five studies $[17,21,23,27,33]$. There was only one study from Iran where Abdolahzadeh et al in 2013 stressed the fact that there is a strong correlation between PL agenesis and left hand dominance. These authors also stated that people with absence of the PL muscle are 3.7 times more likely to have left hand dominance while left handed people are 3.7 times more likely to have agenesis of the PL muscle [34]. This result was not repeated by any other study.

The PL muscle absence in not correlated with other anomalies of the forearm and there have been four studies that came up to this result $[7,17,18,22]$. On the contrary, Yesilada et al (2012) reported the case of a young male that was operated and was found to lack the PL muscle in combination with an anomalous flexor digitorum superficialis (FDS) muscle with a large unique belly [42]. Other important conclusions from the literature were the fact that PL muscle absence is not connected with a decrease in the grip or pinch strength of the hand [43] and the fact that PL tendon is rapidly disappearing in humanity [38].

Apart from PL muscle agenesis, which is the most common anomaly of the muscle, there are other variations that concern the form of the muscle, its attachments, origin, course, position, belly or tendon $[5,6,28,44]$. All these rare anomalies have an overall incidence of $9 \%$ and are seen more often on the right hand $[5,6,28,44]$.

There have been 20 interesting articles in the literature from 1975 to 2014 that reported an anomaly of the PL muscle. Ten of these articles referred to intraoperative observations, nine articles referred to anatomical dissections and only one referred to medical records of magnetic resonance imaging (MRI). The results from the anatomical dissections showed that PL muscle may appear unilaterally reversed $[3,45]$, bi- 
laterally reversed [46, 47], reversed having three bellies [48], unilaterally duplicated [49], bilaterally duplicated [50] and fleshy without the usual distally long tendon [5]. Especially interesting is a study made by Pai et al (2008) who performed anatomical dissections on 30 cadavers and observed that PL muscle was absent in four cadavers while it was reversed in three others [6].

The PL muscle variations can cause symptoms or painful syndromes (carpal tunnel syndrome, Gyon's syndrome) to the upper extremities that can be relieved only after surgical removal of the muscle. Such kinds of cases are reported rarely. In our research, we found 10 articles that referred to intraoperative discovered anomalies of the PL muscle. There have been two authors that reported Gyon's syndrome to patients due to a hypertrophied accessory PL muscle [51] and a reversed PL muscle that was directed to the Guyon's channel [52] respectively. There have been three studies that described anomalous PL muscles in patients that were operated due to carpal tunnel syndrome. In these cases, the PL muscle that was described was either unilaterally reversed (three cases) [53] or hypertrophied and bilaterally reversed [54] or tendinous at its proximal end (1/3), muscular at its distal end (2/3) and terminated in a very short tendon [4]. There have been five cases where patients were operated due to symptoms (pain, paresthesia, numbness, and weakening) on the forearm or the hand. In these cases, the authors reported variations of the PL muscle like absence in combination with an anomalous FDS [42], an epifascial accessory PL muscle [44], a tendinous proximally, fleshy in the middle and tendinous at the upper end PL muscle [8], a three headed reversed PL muscle [55] and a PL muscle that was running anteriorly to the flexor retinaculum before entering the wrist under the surface of the aponeurosis [56]. Finally, the unique article that constituted a retrospective study of medical records of MRI revealed four cases of reversed PL muscles [57].

\section{Conclusions}

The PL muscle has great clinical importance and is classified phylogenetically as a retrogressive muscle $[9,28,37]$. The reasons for its importance are: 1) its tendon is a great landmark to identify the median nerve during operations $[5,44,49]$; 2) the PL tendon is used as an alternative transplant for various reconstructive plastic and hand procedures and as a tendon graft in various positions in otolaryngology and ophthalmology (e.g. lip augmentation, ptosis correction, management of facial paralysis, restoration of lip and chin defects, urinary incontinence, opponensplasty for severe carpal tunnel syndrome and excisional arthroplasty for management of Keinbock's disease) $[7,12,14,31,33]$; 3) PL muscle variations cause a variety of clinical syndromes such as carpal tunnel syndrome, Guyon's syndrome or compartment syndrome of the forearm or the wrist $[3,48,52]$; and 4) research of the PL muscle helps the understanding of the hereditary of genes responsible for the muscles and their functions [18]. The conclusion from our research is that PL muscle is indeed one of the most variable muscles in the human body and its variations must always be in medical practitioners and surgeons' mind in order to deal well with symptoms of the forearm in daily practice.

\section{Conflict of Interest}

The authors declare that there is no conflict of interests regarding the publication of this paper.

\section{References}

1. Schaeffer J Parsons. On the variations of the palmaris longus muscle. Anat Rec. 1909;3(4):275-278.

2. Osonuga A, Mahama HM, Brown AA, Osonuga OA, Serbeh G, Harding AN, Hormeku AK. The Prevalence of Palmaris longus agenesis among the Ghanaian population. Asian Pacific Journal of Tropical Disease. 2012;2:S887S889.

3. Murabit A, Gnarra M, Mohamed A. Reversed palmaris longus muscle: Anatomical variant - case report and literature review. Can J Plast Surg. 2013;21(1):55-56.

4. Guler MM, Celikoz B. Anomalous palmaris longus muscle causing carpal tunnel-like syndrome. Arch Orthop Trauma Surg. 1998;117(4-5):296-297.

5. Natsis K, Didagelos M, Manoli S, Vlasis K, Papathanasiou E, Sofidis G, Nerantzidou X. Fleshy palmaris longus muscle - a cadaveric finding and its clinical significance: a case report. Hippokratia. 2012;16(4):378-380.

6. Pai MM, Prabhu LV, Nayak SR, Madhyastha S, Vadgaonkar R, Krishnamurthy A, Kumar A. The palmaris longus muscle: its anatomic variations and functional morphology. Rom J Morphol Embryol. 2008;49(2):215217.

7. Sharma DC, Pendse V, Sahay K, Soni BL. The changing pattern of maternal and neonatal anemia at Udaipur during 2 decades in relation to poverty, parity, prematurity and vegetarianism. Asia Oceania J Obstet Gynaecol. 1991;17(1):13-17.

8. Bozkurt MC, Tagil SM, Ersoy M, Tekdemir I. Muscle variations and abnormal branching and course of the ulnar nerve in the forearm and hand. Clin Anat. 2004;17(1):6466.

9. Yammine K. Clinical prevalence of palmaris longus agenesis: a systematic review and meta-analysis. Clin Anat. 2013;26(6):709-718.

10. Mbaka GO, Ejiwunmi AB. Prevalence of palmaris longus absence--a study in the Yoruba population. Ulster Med J. 2009;78(2):90-93.

11. Kose O, Adanir O, Cirpar M, Kurklu M, Komurcu M. The prevalence of absence of the palmaris longus: a study in Turkish population. Arch Orthop Trauma Surg. 2009;129(5):609-611.

12. Reimann AF, Daseler EH, Anson BJ, Beaton LE. The palmaris longus muscle and tendon. A study of $1600 \mathrm{ex}-$ tremities. The Anatomical Record. 1994;89(4):495-505.

13. Karimi-Jashni H, Karamatollah R, Abdolreza SJ. Agenesis of palmaris longus in southern of Iran: a polulation based study. OnLine Journal of Biological Sciences. 2013;14(1):8. 
14. Saxena S. A study on the absence/presence of the muscle Palmaris Longus in an Indian population. International J of Healthcare \& Biomedical Research. 2013;2(1):48-53.

15. Enye LA, Saalu LC, Osinubi AA. The prevalence of agenesis of Palmaris longus muscle amongst students in two Lagos-Based Medical schools. Int J Morphol. 2010;28(3):849-854.

16. Oluyemi KA, Adesanya OA, Odion BI, Ukwenya VO. Incidence of palmaris longus muscle absence in Nigerian population. International Journal of Morphology. 2008;26(2):305-308.

17. Sebastin SJ, Lim AY. Clinical assessment of absence of the palmaris longus and its association with other anatomical anomalies-- a Chinese population study. Ann Acad Med Singapore. 2006;35(4):249-253.

18. Raouf HA, Kader GA, Jaradat A, Dharap A, Fadel R, Salem AH. Frequency of palmaris longus absence and its association with other anatomical variations in the Egyptian population. Clin Anat. 2013;26(5):572-577.

19. Kigera JW, Mukwaya S. Frequency of agenesis Palmaris longus through clinical examination--an East African study. PLoS One. 2011;6(12):e28997.

20. Gangata $H$. The clinical surface anatomy anomalies of the palmaris longus muscle in the Black African population of Zimbabwe and a proposed new testing technique. Clin Anat. 2009;22(2):230-235.

21. Hiz Ozcan. Prevalence of the absence of palmaris longus muscle assessed by a new examination test (Hiz-Ediz Test) in the population residing in the area of Van, Turkey. J Clin Exp Invest. 2011;2(3).

22. Offei EB, Abledu JK. Prevalence of agenesis of palmaris longus muscle and its association with sex, body side, handedness and other anomalies of the forearm in a student population in Ghana. Rawal Medical Journal. 2014;39(2):203-207.

23. Kyung DS, Lee JH, Choi IJ, Kim DK. Different frequency of the absence of the palmaris longus according to assessment methods in a Korean population. Anat Cell Biol. 2012;45(1):53-56.

24. Troha F, Baibak GJ, Kelleher JC. Frequency of the palmaris longus tendon in North American Caucasians. Ann Plast Surg. 1990;25(6):477-478.

25. Ceyhan O, Mavt A. Distribution of agenesis of palmaris longus muscle in 12 to 18 years old age groups. Indian J Med Sci. 1997;51(5):156-160.

26. Sater MS, Dharap AS, Abu-Hijleh MF. The prevalence of absence of the palmaris longus muscle in the Bahraini population. Clin Anat. 2010;23(8):956-961.

27. Abu H, Freih O, Jabaiti SK. Absence of the palmaris longus tendon in Mid Eastern population. Journal of the Bahrain Medical Society. 201(20):2.

28. Morais MA, Gomes MS, Helrigle C, Malysz T. Prevalence of agenesis of the palmaris longus muscle in Brazil and its clinics correlation. Braz J Morphol Sci. 2012;29(4):238242.

29. Alves N, Daysi R, Naira FD. Study of frequency of the palmaris longus muscle in Chilean subjects. Int J Morphol. 2011;29(2):485.

30. Sankar KD, Bhanu PS, John SP. Incidence of agenesis of palmaris longus in the Andhra population of India. Indian J Plast Surg. 2011;44(1):134-138.

31. Thompson NW, Mockford BJ, Cran GW. Absence of the palmaris longus muscle: a population study. Ulster Med J. 2001;70(1):22-24.

32. Venter G, Van Schoor AN, Bosman MC. Degenerative trends of the palmaris longus muscle in a South African population. Clin Anat. 2014;27(2):222-226.

33. Karimi JH, Rahmanian K, Jahromi AS. Relation of Palmaris Longus agenesis with hand dominance. Life Science Journal. 2014;11:2.

34. Abdolahzadeh Lahiji F, Ashoori K, Dahmardehei M. Prevalence of palmaris longus agenesis in a hospital in Iran. Arch Iran Med. 2013;16(3):187-188.

35. Soltani AM, Peric M, Francis CS, Nguyen TT, Chan LS, Ghiassi A, Stevanovic MV, et al. The variation in the absence of the palmaris longus in a multiethnic population of the United States: an epidemiological study. Plast Surg Int. 2012;2012:282959.

36. Ndou R, Gangata H, Mitchell B, Ngcongo T, Louw G. The frequency of absence of palmaris longus in a South African population of mixed race. Clin Anat. 2010;23(4):437442.

37. Eric M, Koprivcic I, Vucinic N, Radic R, Krivokuca D, Leksan I, Selthofer R. Prevalence of the palmaris longus in relation to the hand dominance. Surg Radiol Anat. 2011;33(6):481-484.

38. Eric M, Krivokuca D, Savovic S, Leksan I, Vucinic N. Prevalence of the palmaris longus through clinical evaluation. Surg Radiol Anat. 2010;32(4):357-361.

39. Kapoor SK, Tiwari A, Kumar A, Bhatia R, Tantuway $\mathrm{V}$, Kapoor S. Clinical relevance of palmaris longus agenesis: common anatomical aberration. Anat Sci Int. 2008;83(1):45-48.

40. Ertem K, Karakoc Y, Pepele D. The absence of palmaris longus tendon and its contribution to pinch strength in the Anatolian population. J Hand Surg Eur Vol. 2011;36(6):517-518.

41. Roohi SA, Choon-Sian L, Shalimar A, Tan GH, Naicker AS, Rehab M. A study on the absence of palmaris longus in a multiracial population. Malaysian Orthopaedic Journal. 2007;1(1):26-28.

42. Yesilada AK, Tatlidede HS, Cakmak E, Kiyak MV, Kilinc L. Anomalous large unique muscle belly of flexor digitorum superficialis and the absence of palmaris longus in the forearm. J Plast Reconstr Aesthet Surg. 2013;66(1):137139.

43. Sebastin SJ, Lim AY, Bee WH, Wong TC, Methil BV. Does the absence of the palmaris longus affect grip and pinch strength? J Hand Surg Br. 2005;30(4):406-408.

44. Tiengo C, Macchi V, Stecco C, Bassetto F, De Caro R. Epifascial accessory palmaris longus muscle. Clin Anat. 2006;19(6):554-557.

45. Cope JM, Looney EM, Craig CA, Gawron R, Lampros $\mathrm{R}$, Mahoney R. Median nerve compression and reverse palmaris longus. International Journal of Anatomic variations. 2009;2:102-104.

46. Heck L, Campos D. Embryological considerations on the bilateral reversed palmaris longus muscle: a case report in 
human. J Morphol. 2014;31(1):58-61.

47. Salgado G, Cantin M, Inzunza O, Munoz A, Saez J, Macuer M. Bilateral reversed palmaris longus muscle: a rare anatomical variation. Folia Morphol (Warsz). 2012;71(1):52-55.

48. Natsis K, Levva S, Totlis T, Anastasopoulos N, Paraskevas G. Three-headed reversed palmaris longus muscle and its clinical significance. Ann Anat. 2007;189(1):97-101.

49. Paraskevas G, Tzaveas A, Natsis K, Kitsoulis P, Spyridakis I. Failure of palmaris longus muscle duplication and its clinical application. Folia Morphol (Warsz). 2008;67(2):150-153.

50. Takanashi Y, Eda M, Kaidoh T, Inoue T. A case of the bilateral duplicate palmaris longus muscles coupled with the palmaris profundus muscle. Yonago Acta Med. 2012;55(4):75-80.

51. Lal RA, Raj S. Guyons canal syndrome due to accessory palmaris longus muscle: aetiological classification: a case report. Cases J. 2009;2:9146.
52. Ogun TC, Karalezli N, Ogun CO. The concomitant presence of two anomalous muscles in the forearm. Hand ( $\mathrm{N}$ Y). 2007;2(3):120-122.

53. Backhouse KM, Churchill-Davidson D. Anomalous palmaris longus muscle producing carpal tunnel-like compression. Hand. 1975;7(1):22-24.

54. Giunta R, Brunner U, Wilhelm K. [Bilateral reversed palmaris longus muscle--a rare cause of peripheral median nerve compression syndrome. Case report]. Unfallchirurg. 1993;96(10):538-540.

55. Yildiz M, Sener M, Aynaci O. Three-headed reversed palmaris longus muscle: a case report and review of the literature. Surg Radiol Anat. 2000;22(3-4):217-219.

56. Koo CC, Roberts $\mathrm{AH}$. The palmaris longus tendon. Another variation in its anatomy. J Hand Surg Br. 1997;22(1):138-139.

57. Schuurman AH, van Gils AP. Reversed palmaris longus muscle on MRI: report of four cases. Eur Radiol. 2000;10(8):1242-1244. 